\section{RADIOBIOLOGY}

\section{Whole-Body Turnover of Selenium in the Rat}

SELENIUM has recently been shown to be an essential micronutrient for rats ${ }^{1}$ and ruminants ${ }^{2}$. These discoveries have directed attention to the lack of information concerning the metabolism of selenium in subtoxic amounts. The present communication gives results for whole-body turnover, or total excretion, of selenium by the rat over a prolonged period of time.

Hooded rats of the Long-Evans strain were used. They were maintained on a complete stock colony ration (ad libitum) and weighed approximately $150 \mathrm{gm}$. at the time of administration of radioactive selenium ; $0.0011 \mathrm{mc}$. of selenium-75 in physiological saline was administered interperitoneally. The total selenium content of the dose was $0.14 \mathrm{mgm}$. and the selenium was present as sodium selenite. 'The total selenium-75 content of the rats was determined three times daily for the first two days, twice daily for one week and daily for a second week. For measurement, individual rats were placed in a ventilated stainless steel tube and confined to a length approximately equal to that of the rat's body. The rat was then suspended approximately $20 \mathrm{~cm}$. above a seintillation counter for measurement of radiation. The counter used was a standard well-counter operated without the top lead shield. The entire top surface of the crystal was unshielded. The $0 \cdot 269-\mathrm{MeV}$. gamma-ray of selenium-75 was counted, using a single-channel pulse-height analyser and scaler. For calibration, a vial containing an aliquot of the dose was substituted for the rat. The standard error of measurement was $2 \cdot 3$ per cent as determined from duplicate counts ${ }^{3}$. There was no difference in the error of measurement between two operators.

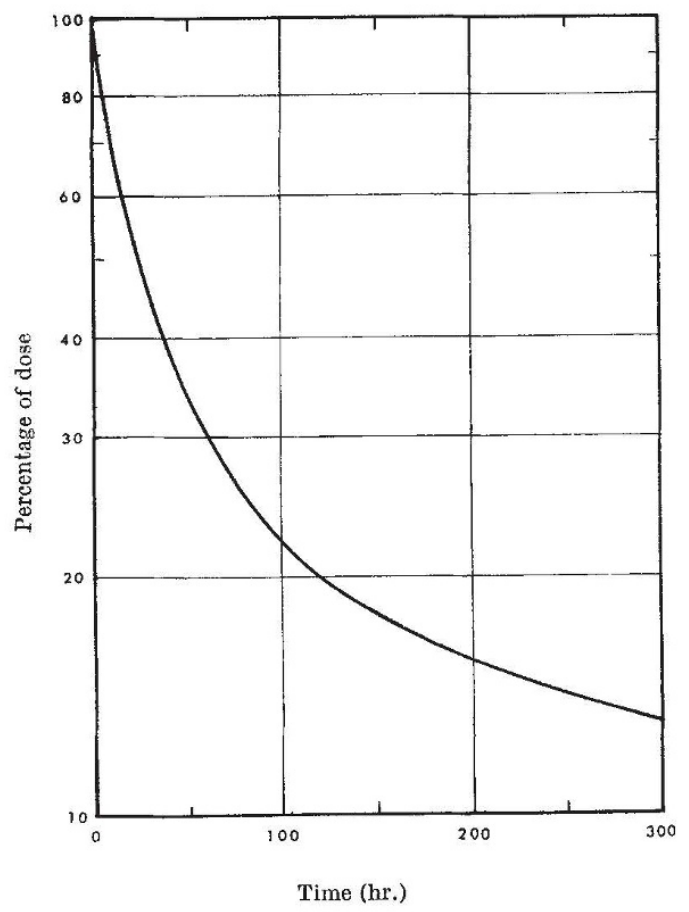

Fig. 1. Radioselenium turnover in the rat
Table 1. WhOLE-BOdy TURNOVER OF SELENIUM IN THE RAT Rat No.

Rate constants $\left(\mathrm{hr} .^{-1}\right)$ :

0
1
2
3
6
7
9
Mean
Standard deviation
$t_{1 / 2}$ (hr.)

$K_{\mathrm{z}}$

$0 \cdot 0025$

$0 \cdot 0018$

$0 \cdot 0021$

0.0023

0.0021

0.0021

$0 \cdot 0022$

318

The results were analysed by considering the wholebody turnover to be describable by a set of consecutive first-order chemical reactions. The rate constants for the various segments of the turnover curve were computed, fitting the data by the method of least squares.

For the first $300 \mathrm{hr}$. after injection of selenium-75, the whole-body turnover may be described by two first-order processes of widely differing rate constants $\left(K_{1}\right.$ and $\left.K_{2}\right)$. A graph presenting the average results is shown in Fig. 1. The initial slope of the curve is determined by $K_{1}$ and the final slope by $K_{2}$. The individual rate constants are presented in Table 1.

Previously published work of selenium metabolism was for periods of less than $50 \mathrm{hr}$. and hence comparison is difficult. Also, other studies measured excretion, rather than retention, and often ignore one of the three routes of selenium excretion-urine, fæces and expired air. Harshfield" found the 'total recoverable selenium' in the rat to be about 75 per cent of dose at $6 \mathrm{hr}$. after injection and about 65 per cent of dose at $12 \mathrm{hr}$. These results agree with the present work. Harshfield found, however, no decrease in 'total recoverable selenium' between 12 and $48 \mathrm{hr}$. post-injection as was found here (see Fig. 1). $\mathrm{McConnell}^{5}$ found the urine and fæcal excretion of selenium-75 from the mouse to be about 45 per cent of dose in the first $24 \mathrm{hr}$. The present work indicates a total excretion of about 48 per cent of dose in an equivalent time. Heinrich and Kelsey ${ }^{6}$ reported the 'total recoverable selenium' in the mouse to be only 16.5 per cent of dose at $48 \mathrm{hr}$. after injection-considerably less than that found here for the rat.

The presence of two rate constants governing selenium turnover indicates that selenium is involved in the metabolism of the animal. Selenium is transferred from one (rapidly excreted) form to another (slowly excreted) form. Two choices are available: (1) the rate-limiting processes are the renal clearance of two chemically different forms of selenium; and (2) the rate-limiting process for the smaller rate constant is the rate of release of selenium from tissues in which it is fixed.

I acknowledge the assistance of Miss July Grafton with the laboratory procedures and Dr. W. B. Dye for his encouragement and counsel.

\title{
Clifton Blincon
}

Department of Agricultural Chemistry, Max C. Fleischmann College of Agriculture, University of Nevada, Reno.

${ }^{1}$ Sehwarz, K., and Foltz, C. M., J. Agric. Chem. Sci., 79, 3292 (1957). ${ }^{3}$ Muth, O. H., Olfeld, J. E., Remmert, L. F., and Schubert, J. R. Science, 128, 1090 (i958)

s Youden, W. J., "Statistical Methods for Chemists", 16 (Wiley, New York, 1951)

- Harshfleld, R. D., "A Study on the Metabolism of Selenium"75 in the Mouse", M.A. thesis, University of South Dakota (1953).

${ }^{5}$ MeConnell, K. P., J. Biol. Chem., 141, 427 (1941).

'Heinrich, M., and Kelsey, F. E., J. Pharmacol. Exp. Therap., 114, 28 (1953). 